\title{
ОСОБЕННОСТИ ПНЕВМОНИЙ, ВЫЗВАННЫХ НОВЫМ \\ КОРОНАВИРУСОМ SARS-COV-2 (ОБЗОР ЛИТЕРАТУРЫ)
}

Базыкина Е.А., Троценко О.Е., Корита Т.В., Балахонцева Л.А., Котова В.О. ФБУН Хабаровский НИИ эпидемиологии и микробиологии

Роспотребнадзора, г. Хабаровск

\section{Резюме:}

Проведен анализ научных публикаций по вопросам основ патогенеза, лабораторной и рентгенологической картины пневмоний, а также вопросов ко-инфицирования у больных с SARS-CoV-2. На основе имеющихся в мировой научной литературе сведений дана оценка чувствительности методам компьютерной томографии и полимеразной цепной реакции. Наряду со сбором эпидемиологического анамнеза, обоснована необходимость применения как лабораторных, так и лучевых методов диагностики для наиболее достоверного выявления пациентов с новой коронавирусной пневмонией.

Ключевые слова: SARS-CoV-2, пневмония, полимеразная цепная реакция, компьютерная томография, ко-инфекция

\section{Введение}

На протяжении многих столетий человечество не раз сталкивалось с пандемиями. Только в XIX столетии летописцами было зарегистрировано 4 пандемии гриппа, а в XX столетии вспыхнула одна из наиболее смертоносных - пандемия 1918 г., широко известная как «испанка», унесшая около 20 миллионов жизней [1].

В XXI веке человечество столкнулось с новым, ранее неизвестным возбудителем острого тяжелого респираторного синдрома, вызванного вирусом SARS-CoV-2. В целом семейство коронавирусов широко распространено как среди людей, так и других позвоночных. Возбудители вызывают поражение респираторного и гастроинтестинального трактов 
(энтериты, гепатиты), а также неврологические нарушения у заболевших. В 2003 году на Ближнем Востоке был выявлен вирус, вызывающий острый тяжелый респираторный синдром (SARS-CoV), через 9 лет новая эпидемия была вызвана коронавирусом MERS-CoV. Особенностями данных двух эпидемий были более высокие уровни летальности $(40$ и $10 \%$ соответственно), а также значительно меньшая трансмиссивность по сравнению с современной пандемией SARS-CoV-2. Например, индекс репродукции для SARS-CoV-2 (R0, репродуктивное число - параметр, характеризующий инфекционность вируса, т.е. число здоровых неиммунных людей, которых может заразить один заболевший) составляет примерно 2,2, что оказалось выше R0 для MERS-CoV $(0,45-0,98)[2,3,4,6]$.

Основными механизмами передачи SARS-CoV-2 являются аэрогенный, реализуемый как правило посредством воздушно-капельного пути передачи, и контактный механизм (контактно-бытовой путь). Теоретически возможны фекально-оральный, гемоконтактный и вертикальный пути передачи, так как методом ПЦР РНК вируса была выделена из фекалий, мочи и плазмы крови пациентов [4, 6]. Однако, по данным Всемирной Организации Здравоохранения, официально зарегистрированных случаев передачи заболевания указанными механизмами не установлено [5].

\section{Патогенез}

Известно, что для SARS-CoV-2 характерно преимущественное поражение нижних респираторных путей. Вирус связывается с ангиотензиновыми рецепторами 2 типа альвеолоцитов и в последующем значительно изменяет цитокиновый гомеостаз, приводя к цитокиновому «шторму» или «каскаду», что в сочетании с дыхательной недостаточностью,

вызванной синтезом фибрина фибробластами с последующим формированием гиалуроновых мембран в тканях легкого, а также повреждением и десквамацией альвеолоцитов 2 типа, считается основным патогенетическим механизмом, приводящим к серьезным нарушениями 
функции внутренних органов. Помимо легких, поражаются сердечнососудистая система, желудочно-кишечный тракт и почки $[2,7,8,21]$.

В наиболее тяжелых случаях заболевания зарегистрированы следующие лабораторные изменения - прогрессирующее повышенные уровней IL-6, C-реактивного белка, мочевины, азота мочевины, лактатдегидрогеназы (ЛДГ) креатинина, I-тропонина, а также увеличение количества нейтрофилов, возможно снижение лимфоцитарного пула [9, 10, $11,12,13]$. Выраженные изменения претерпевает и свертывающая система у пациентов, инфицированных SARS-CoV-2. Так, уровень D-димера значительно повышается, что приводит к быстрому развитию коагулопатии, формированию микротромбов вплоть до возникновения ДВС-синдрома. Причем повышенный уровень D-димера прямо коррелирует с тяжестью процесса и наиболее часто повышается у пациентов с летальным исходом $[14,13,15,16]$.

Методом цитофлуориметрии учеными были выявлены следующие особенности изменения лейкоцитарных фракций у пациентов с пневмонией, вызванной SARS-CoV-2 - пропорционально увеличению степени тяжести снижались уровни CD8+, В-клеток, CD3+CD8+, CD4+ лимфоцитов, и натуральных киллеров, изменялось соотношение $\mathrm{CD} 4+/ \mathrm{CD} 8+$. Более значительное снижение CD8+, CD3+CD8+ и B-клеток, а также увеличение соотношения CD4+/CD8+ были предикторами неблагоприятного исхода пневмонии у инфицированных лиц $[17,18]$.

\section{Ко-инфекции}

У пациентов с тяжелым течением вирусной пневмонии, вызванной SARS-CoV-2, актуальным является изучение различных вариантов коинфицирования, например, бактериальными, грибковыми патогенами, а также другими вирусами, в особенности при подключении к аппарату искусственной вентиляции легких (ИВЛ). Многие ученые и врачи в проведенных исследованиях показали, что ИВЛ может усугублять прогноз 
заболевания вследствие развития вентилятор-ассоциированных заболеваний $[19,20,21,22]$.

Согласно проведенному мета анализу, у пациентов, госпитализированных с новой коронавирусной инфекцией, бактериальная коинфекция в целом развивается в 7\% случаев, что значительно ниже, чем по сравнению с гриппозными пневмониями (19,5\%). Однако показано, что у пациентов с SARS-CoV-2, находящихся в отделениях интенсивной терапии, бактериальная ко-инфекция развивалась в 3,5 раза чаще, чем у больных, получающих лечение в других общих отделениях - в 14\% и 4\% случаев, соответственно. Чаще всего ко-инфекция была вызвана Mycoplasma pneumonia (42\%), Pseudomonas aeruginosa (12\%) и Haemophilus influenzae $(12 \%)$.

Ко-инфицирование пациентов пневмониями новой коронавирусной этиологии несколькими вирусами в целом выявлялось у 3\% заболевших, наиболее часто у них изолировали респираторно-синцитиальный вирус (16,9\%) и грипп типа A (15,5\%). Были зафиксированы единичные случаи коинфицирования грибковыми патогенами, среди которых чаще выделялись Candida albicans, Aspergillus flavus, Aspergillus fumigatus и Candida glabrata. Сочетанное инфицирование синегнойной палочкой, а также коинфицирование патогенными грибковыми агентами косвенно указывает на значительный вклад внутрибольничного инфицирования вследствие длительной госпитализации пациентов с SARS-CoV-2 [23, 24].

Помимо перечисленных возбудителей бактериальных пневмоний, некоторые авторы указывают на роль золотистого стафилококка (Staphylococcus aureus), пневмококка (Streptococcus pneumoniae) и микобактерии туберкулеза (Mycobacterium tuberculosis) в развитии коинфекции у пациентов с новой коронавирусной пневмонией, в связи с чем практикующим врачам рекомендовано уделять большое внимание не только диагностике PHK SARS-CoV-2 у больных с признаками поражения легких, но и других патогенов для своевременного назначения наиболее 
эффективного лечения, что позволит улучшить исход заболевания, так как известно, что ко-инфекция приводит к увеличению летальности [25, 26, 27, 28].

\section{Диагностика}

Исследователи из Китайской Народной Республики и Южной Кореи обратили внимание на некоторые клинические и рентгенологические особенности пневмоний, вызванных SARS-CoV-2, по сравнению с обычной внебольничной пневмонией: у пациентов с новой коронавирусной инфекцией отмечены более высокая температура тела и более выраженные признаки диспноэ. При инфицировании SARS-CoV-2 компьютерная томография (KT) выявляет очаговые изменения рентгенологической картины по типу «матового стекла». Зачастую характерными оказывались единичные очаги размером до сантиметра с картиной «матового стекла», находящиеся вблизи бронхососудистых пучков. У лиц с внебольничной пневмонией другой этиологии на снимках легких чаще регистрировались участки повышенной плотности [29, 30, 31]. Пневмонии, вызванной SARS-CoV-2, присущи вариативность и динамическое изменение рентгенологической картины. Показано, что одностороннее поражение легкого в виде единичных участков «матового стекла» быстро переходит в двустороннее поражение с дальнейшим развитием инфильтрации и уплотнением долей легких, вплоть до формирования рентгенологической картины фиброза, что может затруднять дифференциальную диагностику с пневмониями, вызванными другими возбудителями [32, 33].

Редкими осложнениями пневмонии, вызванной новой коронавирусной инфекцией, можно считать формирование спонтанного пневмомедиастимума (эмфиземы), буллезной эмфиземы и пневмоторакса [34, 35]

При этом, дифференциальная диагностика пневмоний, вызванных SARS-CoV-2, остается сложной задачей, несмотря на разработанные алгоритмы ПЦР и лучевые методы диагностики. На начальных этапах пандемии при диагностике пневмонии, обусловленной SARS-CoV-2, 
преимущественное внимание уделяли эпидемиологическому анамнезу (район проживания, факт посещения неблагоприятных по заболеванию мест, наличие контактов с заболевшими или прибывшими из неблагополучных регионов), что позволяло, в случае получения сомнительных результатов ПЦР при исследовании респираторных мазков, облегчить постановку правильного диагноза.

На современном этапе в связи с повсеместным распространением новой коронавирусной инфекции такая этиологическая расшифровка пневмоний в определенных случаях может вызвать затруднения, в том числе у опытного врача-инфекциониста [36, 37]. Так, по данным ряда авторов, установлено, что исследования мазков из ротоглотки не всегда являются достаточно информативными для своевременного выявления новой коронавирусной инфекции у пациентов с пневмониями. Во многих работах показано, что наиболее оптимальным видом биологического материала является мокрота. Например, проведенное в Китае исследование показало значимо более высокую долю положительных на PHK SARS-CoV-2 проб мокроты (76,9\%) по сравнению с мазками из ротоглотки $(44,2 \%)$ у больных с подозрением на пневмонию, вызванную SARS-CoV-2. Авторы считают, что мазки из ротоглотки актуальны в случае массового освидетельствования граждан на наличие SARS-CoV-2, в ходе эпидемиологического расследования, при обследовании контактных лиц, а также в случае невозможности отделения мокроты у пациентов с уже развившейся инфекцией [38, 39, 40].

Описаны случаи течения пневмонии как с отсутствием повышенной температуры тела, респираторных симптомов, так и наличием типичных признаков инфекционного заболевания у лиц с отрицательным ПЦРанализом мазков из ротоглотки, но с наличием характерных изменений на снимках KT, причем впоследствии у наблюдаемых пациентов PHK SARSCoV-2 обнаруживалась в мокроте [41, 42, 43, 44, 45, 46]. 
Сравнительное исследование легких методом компьютерной томографии и мазков из носо- и ротоглотки путем ПЦР, проведенное у больных с подозрением на пневмонию, показало большую чувствительность у первого из них по сравнению со вторым методом (97,2-98,0\% и 71,0-83,3\%, соответственно). Авторы пришли к выводу о том, что выявленные различия могут быть обусловлены недостаточной чувствительностью тест-систем, низкой вирусной нагрузкой в респираторном мазке пациента с подозрением на пневмонию, неправильным забором биологического материала, несоблюдением требований транспортировки образцов. В целом, исследователи подтвердили, что лабораторное освидетельствование методом ПЦР, причём преимущественно мокроты, и проведение лучевой диагностики являются крайне важными для диагностики пневмонии, обусловленной новой коронавирусной инфекцией $[47,48,49,50,51]$.

Несмотря на безусловные достоинства компьютерной томографии, следует учитывать высокую лучевую нагрузку на организм человека, которая возникает в случае частого проведения рентгенологических исследований, в связи с чем, исследователи рекомендуют проведение низко дозированной КТ. В алгоритм лучевой диагностики также предлагается внедрить искусственный интеллект, что позволит снизить вероятность ошибки и повысить качество проведенного обследования [52, 53].

Таким образом, пневмонии, вызванные SARS-CoV-2, характеризуются изменениями в клеточном звене иммунитета, в соотношении субпопуляций лимфоцитов. В организме инфицированного человека возникает «цитокиновый шторм», который в свою очередь приводит к активации таких процессов как фиброз легких.

Возникновение ко-инфекции у таких пациентов является относительно редким явлением, однако в отделениях интенсивной терапии риск формирования ко-инфекции значительно увеличивается, не исключено инфицирование бактериальными, грибковыми и вирусными возбудителями пациентов с новой коронавирусной инфекцией. 
Диагностика пневмонии, обусловленной SARS-CoV-2, в некоторых случаях может представлять сложность в связи с тем, что ПЦР, проведенная для биологического материала, полученного только из носо/ротоглотки, может дать ложноотрицательный результат. Кроме того, существует определенный риск и в неверной интерпретации рентгенологической картины. В связи с этим, наряду с обязательным эпидемиологическим анамнезом, дополнительное исследование мокроты (или бронхоальвеолярного лаважа) на наличие РНК нового коронавируса и точная трактовка результатов лучевой диагностики являются необходимыми условиями для подтверждения COVID-19.

\section{Список литературы:}

1. Брико Н.И. 100 лет пандемии: уроки истории. Новый этап вакцинопрофилактики. Эпидемиология и вакцинопрофилактика. 2018; 4 (17): 68-75.

2. Jiang, F., Deng, L., Zhang, L. et al. Review of the Clinical Characteristics of Coronavirus Disease 2019 (COVID-19). J GEN INTERN MED 35, 15451549 (2020). https://doi.org/10.1007/s11606-020-05762-w.

3. Park J., Soyoung J., Aeran K., Park J. MERS transmission and risk factors: a systematic review. BMC Public Health (2018) 18:574; Wang, Yixuan et al. "Unique epidemiological and clinical features of the emerging 2019 novel coronavirus pneumonia (COVID-19) implicate special control measures. Journal of medical virology. vol. 92, 6 (2020): 568-576. doi:10.1002/jmv.25748.

4. Jin Y.H., Cai L., Cheng Z.S., et al. A rapid advice guideline for the diagnosis and treatment of 2019 novel coronavirus (2019-nCoV) infected pneumonia (standard version). Mil Med Res. 2020;7(1):4. doi:10.1186/s40779-020-0233-6.

5. Электронный ресурс. Дата обращения 18.07.2020 г. // www.who.int/news-room/commentaries/detail/transmission-of-sars-cov-2implications-for-infection-prevention-precautions. 
6. Wang Y., Wang Y., Chen Y., Qin Q. Unique epidemiological and clinical features of the emerging 2019 novel coronavirus pneumonia (COVID-19) implicate special control measures. J Med Virol. 2020;92(6):568-576. doi:10.1002/jmv.25748.

7. Hu Y., Deng H., Huang L., Xia L., Zhou X. Analysis of Characteristics in Death Patients with COVID-19 Pneumonia without Underlying Diseases. Acad Radiol. 2020;27(5):752. doi:10.1016/j.acra.2020.03.023.

8. García L.F. Immune Response, Inflammation, and the Clinical Spectrum of COVID-19. Front Immunol. 2020;11:1441. doi:10.3389/fimmu.2020.01441.

9. Lin L., Lu L., Cao W., Li T. Hypothesis for potential pathogenesis of SARSCoV-2 infection-a review of immune changes in patients with viral pneumonia. Emerg Microbes Infect. 2020;9(1):727-732. doi:10.1080/22221751.2020.1746199.

10.Li L., Zhang B., He B., Gong Z., Chen X. Critical patients with coronavirus disease 2019: Risk factors and outcome nomogram. $J$ Infect. 2020;80(6):e37-e38. doi:10.1016/j.jinf.2020.03.025.

11.Wang F., Nie J., Wang H., et al. Characteristics of Peripheral Lymphocyte Subset Alteration in COVID-19 Pneumonia. $J$ Infect Dis. 2020;221(11):1762-1769. doi:10.1093/infdis/jiaa150.

12. Liu Y., Yang Y., Zhang C., et al. Clinical and biochemical indexes from 2019-nCoV infected patients linked to viral loads and lung injury. Sci China Life Sci. 2020;63(3):364-374. doi:10.1007/s11427-020-1643-8.

13.Liu X., Zhou H., Zhou Y., et al. Risk factors associated with disease severity and length of hospital stay in COVID-19 patients. J Infect. 2020;81(1):e95e97. doi:10.1016/j.jinf.2020.04.008.

14.Li L., Zhang B., He B., Gong Z., Chen X. Critical patients with coronavirus disease 2019: Risk factors and outcome nomogram. $J$ Infect. 2020;80(6):e37-e38. doi:10.1016/j.jinf.2020.03.025.

15.Porfidia A., Pola R. Venous thromboembolism in COVID-19 patients. J Thromb Haemost. 2020;18(6):1516-1517. doi:10.1111/jth.14842. 
16.Guevara-Noriega K.A., Lucar-Lopez G.A., Nuñez G., Rivera-Aguasvivas L., Chauhan I. Coagulation Panel in Patients with SARS-CoV2 Infection (COVID-19). Ann Clin Lab Sci. 2020;50(3):295-298.

17.Wang F., Nie J., Wang H., et al. Characteristics of Peripheral Lymphocyte Subset Alteration in COVID-19 Pneumonia. $J$ Infect Dis. 2020;221(11):1762-1769. doi:10.1093/infdis/jiaa150.

18.Du R.H., Liang L.R., Yang C.Q., et al. Predictors of mortality for patients with COVID-19 pneumonia caused by SARS-CoV-2: a prospective cohort study. Eur Respir J. 2020;55(5):2000524. Published 2020 May 7. doi:10.1183/13993003.00524-2020.

19.Póvoa HC.C., Chianca G.C., Iorio N.L.P.P. COVID-19: An Alert to Ventilator-Associated Bacterial. Infect Dis Ther. 2020;1-4. doi:10.1007/s40121-020-00306-5.

20.Yang X., Yu Y., Xu J., et al. Clinical course and outcomes of critically ill patients with SARS-CoV-2 pneumonia in Wuhan, China: a single-centered, retrospective, observational study. Lancet Respir Med. 2020;8(5):475-481. doi:10.1016/S2213-2600(20)30079-5.

21.Wu J.H., Li X., Huang B., Su H., Li Y., Luo D.J., Chen S., Ma L., Wang S.H., Nie X., Peng L. [Pathological changes of fatal coronavirus disease 2019 (COVID-19) in the lungs: report of 10 cases by postmortem needle autopsy]. Zhonghua Bing Li Xue Za Zhi. 2020;49(6):568-575.

22.Орлова, О.А., Акимкин, В. Г.. Организация эпидемиологической диагностики вентилятор-ассоциированных инфекций дыхательных путей. Медицинский алфавит. 2017; 3(30): 15-19.

23.Lansbury L., Lim B., Baskaran V., Lim W.S. Co-infections in people with COVID-19: a systematic review and meta-analysis. J Infect. 2020;S01634453(20)30323-6. doi:10.1016/j.jinf.2020.05.046.

24.Teng F., Liu X., Guo S.B., et al. Community-acquired bacterial co-infection predicts severity and mortality in influenza-associated pneumonia admitted 
patients. $\quad J \quad$ Infect $\quad$ Chemother. 2019;25(2):129-136. doi:10.1016/j.jiac.2018.10.014.

25.Kreitmann L., Monard C., Dauwalder O., Simon M., Argaud L. Early bacterial co-infection in ARDS related to COVID-19. Intensive Care Med. 2020;1-3. doi:10.1007/s00134-020-06165-5.

26.Cucchiari D., Pericàs J.M., Riera J., et al. Pneumococcal superinfection in COVID-19 patients: A series of 5 cases. Med Clin (Barc). 2020;S00257753(20)30349-3. doi:10.1016/j.medcli.2020.05.022.

27.Chaudhary WA, Chong PL, Mani BI, et al. Primary Respiratory Bacterial Coinfections in Patients with COVID-19. Am J Trop Med Hyg. 2020;10.4269/ajtmh.20-0498. doi:10.4269/ajtmh.20-0498.

28.Hughes S., Troise O., Donaldson H., Mughal N., Moore L.S. Bacterial and fungal coinfection among hospitalised patients with COVID-19: A retrospective cohort study in a UK secondary care setting. Clin Microbiol Infect. 2020;S1198-743X(20)30369-4. doi:10.1016/j.cmi.2020.06.025.

29.Xia T., Li J., Gao J., Xu X. Small Solitary Ground-Glass Nodule on CT as an Initial Manifestation of Coronavirus Disease 2019 (COVID-19) Pneumonia. Korean J Radiol. 2020;21(5):545-549. doi:10.3348/kjr.2020.0240.

30.Zhou Y., Guo S., He Y., et al. COVID-19 Is Distinct From SARS-CoV-2Negative Community-Acquired Pneumonia. Front Cell Infect Microbiol. 2020;10:322. Published 2020 Jun 16. doi:10.3389/fcimb.2020.00322.

31.Song F., Shi N., Shan F., et al. Emerging 2019 Novel Coronavirus (2019nCoV) Pneumonia. Radiology. 2020;295(1):210-217. doi:10.1148/radiol.2020200274.

32.Shi H., Han X., Jiang N., et al. Radiological findings from 81 patients with COVID-19 pneumonia in Wuhan, China: a descriptive study. Lancet Infect Dis. 2020;20(4):425-434. doi:10.1016/S1473-3099(20)30086-4.

33.Pan Y., Guan H., Zhou S., et al. Initial CT findings and temporal changes in patients with the novel coronavirus pneumonia (2019-nCoV): a study of 63 
patients in Wuhan, China. Eur Radiol. 2020;30(6):3306-3309. doi:10.1007/s00330-020-06731-x.

34.Sun R., Liu H., Wang X. Mediastinal Emphysema, Giant Bulla, and Pneumothorax Developed during the Course of COVID-19 Pneumonia. Korean J Radiol. 2020;21(5):541-544. doi:10.3348/kjr.2020.0180.

35.Wang J., Su X., Zhang T., Zheng C. Spontaneous Pneumomediastinum: A Probable Unusual Complication of Coronavirus Disease 2019 (COVID-19) Pneumonia. Korean J Radiol. 2020;21(5):627-628. doi:10.3348/kjr.2020.0281.

36.Tian X.L., Peng M., Wang H.P., Cai B.Q., Xu W.B., Zhu Y.J., Li T.S., Zhu H.D., Song L., Wang M.Z., Zhang L., Shi J.H. [The differential diagnosis for novel coronavirus pneumonia and similar lung diseases in general hospitals]. Zhonghua Jie He He Hu Xi Za Zhi. 2020 May 12;43(5):401-408. Chinese. doi: 10.3760/cma.j.cn112147-20200221-00136. PMID: 32153167.

37.Sun R., Liu H., Wang X. Mediastinal Emphysema, Giant Bulla, and Pneumothorax Developed during the Course of COVID-19 Pneumonia. Korean J Radiol. 2020;21(5):541-544. doi:10.3348/kjr.2020.0180.

38.Hase R., Kurita T., Muranaka E., Sasazawa H., Mito H., Yano Y. A case of imported COVID-19 diagnosed by PCR-positive lower respiratory specimen but with PCR-negative throat swabs. Infect Dis (Lond). 2020;52(6):423-426. doi:10.1080/23744235.2020.1744711.

39.Hornuss D., Laubner K., Monasterio C., Thimme R., Wagner D. COVID19-assoziierte Pneumonie trotz persistierend negativen PCR-Tests aus oropharyngealen Abstrichen [COVID-19 associated pneumonia despite repeatedly negative PCR-analysis from oropharyngeal swabs]. Dtsch Med Wochenschr. 2020;145(12):844-849. doi:10.1055/a-1170-6061.

40. Lin C., Xiang J., Yan M., Li H., Huang S., Shen C. Comparison of throat swabs and sputum specimens for viral nucleic acid detection in 52 cases of novel coronavirus (SARS-Cov-2)-infected pneumonia (COVID-19). Clin Chem Lab Med. 2020;58(7):1089-1094. doi:10.1515/cclm-2020-0187. 
41.Bhat R., Hamid A., Kunin J.R., et al. Chest Imaging in Patients Hospitalized With COVID-19 Infection - A Case Series. Curr Probl Diagn Radiol. 2020;49(4):294-301. doi:10.1067/j.cpradiol.2020.04.001.

42.Sivakorn C., Luvira V., Muangnoicharoen S., et al. Case Report: Walking Pneumonia in Novel Coronavirus Disease (COVID-19): Mild Symptoms with Marked Abnormalities on Chest Imaging. Am J Trop Med Hyg. 2020;102(5):940-942. doi:10.4269/ajtmh.20-0203.

43.Hase R., Kurita T., Muranaka E., Sasazawa H., Mito H., Yano Y. A case of imported COVID-19 diagnosed by PCR-positive lower respiratory specimen but with PCR-negative throat swabs. Infect Dis (Lond). 2020;52(6):423-426. doi:10.1080/23744235.2020.1744711.

44.Long C., Xu H., Shen Q., et al. Diagnosis of the Coronavirus disease (COVID-19): rRT-PCR or CT?. Eur J Radiol. 2020;126:108961. doi:10.1016/j.ejrad.2020.108961.

45. Lin C., Ding Y., Xie B., et al. Asymptomatic novel coronavirus pneumonia patient outside Wuhan: The value of CT images in the course of the disease. Clin Imaging. 2020;63:7-9. doi:10.1016/j.clinimag.2020.02.008.

46.Fechner C., Strobel K., Treumann T., et al. COVID-19 and the role of imaging: early experiences in Central Switzerland. Swiss Med Wkly. 2020;150:w20304. Published 2020 Jun 22. doi:10.4414/smw.2020.20304.

47.Zheng Z., Yao Z., Wu K., Zheng J. The diagnosis of pandemic coronavirus pneumonia: A review of radiology examination and laboratory test. J Clin Virol. 2020;128:104396. doi:10.1016/j.jcv.2020.104396.

48.Tenda E.D., Yulianti M., Asaf M.M., et al. The Importance of Chest CT Scan in COVID-19. Acta Med Indones. 2020;52(1):68-73.

49.Ai T., Yang Z., Hou H., et al. Correlation of Chest CT and RT-PCR Testing for Coronavirus Disease 2019 (COVID-19) in China: A Report of 1014 Cases. Radiology. 2020;296(2):E32-E40. doi:10.1148/radiol.2020200642. 
50.Long C., Xu H., Shen Q., et al. Diagnosis of the Coronavirus disease (COVID-19): rRT-PCR or CT?. Eur J Radiol. 2020;126:108961. doi:10.1016/j.ejrad.2020.108961.

51.Fang Y., Zhang H., Xie J., et al. Sensitivity of Chest CT for COVID-19: Comparison to RT-PCR. Radiology. 2020;296(2):E115-E117. doi:10.1148/radiol.2020200432.

52.Kang Z., Li X., Zhou S. Recommendation of low-dose CT in the detection and management of COVID-2019. Eur Radiol. 2020;30(8):4356-4357. doi:10.1007/s00330-020-06809-6.

53. Kim H. Outbreak of novel coronavirus (COVID-19): What is the role of radiologists?. Eur Radiol. 2020;30(6):3266-3267. doi:10.1007/s00330-02006748-2.

\section{Сведения об авторах:}

Базыкина Елена Анатольевна - младший научный сотрудник лаборатории эпидемиологии и профилактики вирусных гепатитов и СПИД; ФБУН Хабаровский научно-исследовательский институт эпидемиологии и микробиологии Роспотребнадзора, Россия, 680000, г. Хабаровск, ул. Шевченко, д. 2

Троценко Ольга Евгеньевна - доктор медицинских наук, директор ФБУН Хабаровский научно-исследовательский институт эпидемиологии и микробиологии Роспотребнадзора, Россия, 680000, г. Хабаровск, ул. Шевченко, д. 2

Корита Татьяна Васильевна - кандидат медицинских наук, ученый секретарь ФБУН Хабаровский научно-исследовательский институт эпидемиологии и микробиологии Роспотребнадзора, Россия, 680000, г. Хабаровск, ул. Шевченко, д. 2

Балахонцева Людмила Анатольевна - руководитель Дальневосточного окружного центра по профилактике и борьбе со СПИД ФБУН Хабаровский научно-исследовательский институт эпидемиологии и микробиологии Роспотребнадзора, Россия, 680000, г. Хабаровск, ул. Шевченко, д. 2

Котова Валерия Олеговна - заведующая лабораторией профилактики вирусных гепатитов и СПИДа ФБУН Хабаровский научно- 
исследовательский институт эпидемиологии и микробиологии Роспотребнадзора, Россия, 680000, г. Хабаровск, ул. Шевченко, д. 2 